\title{
Preclinical modeling of combined phosphatidylinositol-3-kinase inhibition with endocrine therapy for estrogen receptor-positive breast cancer
}

Cesar G Sanchez ${ }^{1,2+}$, Cynthia X Ma ${ }^{2,3+}$, Robert J Crowder ${ }^{2}$, Therese Guintoli², Chanpheng Phommaly ${ }^{2}$, Feng Gao ${ }^{4}$, Li Lin ${ }^{2}$ and Matthew J Ellis ${ }^{2,3^{*}}$

\begin{abstract}
Introduction: Inhibition of phosphatidylinositol-3-kinase (PI3K) induces apoptosis when combined with estrogen deprivation in estrogen receptor (ER)-positive breast cancer. The aims of the present study were to identify effective PI3K pathway inhibitor and endocrine therapy combinations, to evaluate the effect of PI3K pathway mutations and estrogen dependency on tumor response, and to determine the relevance of PIK3CA mutation in recurrent disease.
\end{abstract}

Methods: The PI3K catalytic subunit inhibitor BKM120, the mammalian target of rapamycin (mTOR) inhibitor RAD001 and the dual PI3K/mTOR inhibitor BGT226 were tested against ER-positive breast cancer cell lines before and after long-term estrogen deprivation (LTED). The impact of estradiol deprivation and the ER downregulator fulvestrant on PI3K pathway inhibitor-induced apoptosis was assessed. PIK3CA hotspot mutation analysis was performed in 51 recurrent or metastatic breast cancers and correlated with ER status and survival.

Results: Drug-induced apoptosis was most marked in short-term estrogen-deprived cells with PIK3CA mutation and phosphatase and tensin homolog loss. Apoptosis was most highly induced by BGT226, followed by BKM120, and then RAD001. Estradiol antagonized PI3K inhibitor-induced apoptosis following short-term estrogen deprivation, emphasizing a role for estrogen-deprivation therapy in promoting PI3K inhibitor activity in the first-line setting. ERpositive MCF7 LTED cells exhibited relative resistance to PI3K pathway inhibition that was reversed by fulvestrant. In contrast, T47D LTED cells exhibited ER loss and ER-independent PI3K agent sensitivity. PIK3CA mutation was prevalent in relapsed ER-positive disease (48\%) and was associated with persistent ER positivity and a late relapse pattern.

Conclusions: Estrogen deprivation increased the apoptotic effects of PI3K and dual PI3K/mTOR inhibitors in ERpositive disease, providing a rationale for PI3K/aromatase inhibitor combinations as first-line therapy. In LTED cells, differential effects on ER expression may be a relevant consideration. When ER was persistently expressed, fulvestrant strongly promoted PI3K drug activity. When ER was lost, PI3K inhibitor monotherapy was sufficient to induce high-level apoptosis. Although tumors with PIK3CA mutation had a late recurrence pattern, these mutations were common in metastatic disease and were most often associated with persistent ER expression. Targeting PIK3CA mutant tumors with a PI3K pathway inhibitor and fulvestrant is therefore a feasible strategy for aromataseinhibitor-resistant ER-positive relapsed breast cancer.

\footnotetext{
* Correspondence: MEllis@DOM.wustl.edu

† Contributed equally

${ }^{2}$ Division of Oncology, Department of Medicine, Washington University in St

Louis, 660 S Euclid Avenue, Campus Box 8069, St Louis, MO 63110, USA

Full list of author information is available at the end of the article
} 


\section{Introduction}

Since the widespread adoption of tamoxifen, modest improvements in patient outcomes have been observed in estrogen receptor (ER)-positive breast cancer patients through the introduction of aromatase inhibitors and fulvestrant, but prognosis remains poor for many patients [1] due to de novo or acquired endocrine therapy resistance. A major biological barrier to successful treatment of ER-positive disease is that endocrine treatment induces cell cycle arrest but not high-level cell death [2,3]. Disseminated ER-positive breast cancer cells therefore persist, acquire endocrine therapy resistance and cause disease progression and death. An ideal regimen for ER-positive disease would effectively delete ER-positive cells, thereby circumventing secondary resistance and obviating the requirement for long-term endocrine treatment with its attendant quality-of-life detriment, chronic toxicity and expense.

Targeting the pro-survival phosphatidylinositol-3kinase (PI3K) signaling is intriguing in this regard. Genes in the PI3K pathway are frequently mutated or amplified in ER-positive breast cancer, suggesting that hyperactivation of PI3K signaling is a key target that, if effectively inhibited, could improve outcomes [4]. We have already shown that estrogen deprivation in combination with PI3K inhibition by RNA interference induces synthetic lethality and promotes cell death in ER-positive breast cancer cell lines [5], providing a rational for combination approaches that target the ER and PI3K pathways simultaneously. ER-positive breast cancers are genetically heterogeneous, however, and cell-intrinsic factors may modulate sensitivity to this approach. It is unclear whether mutations in PI3K pathway proteins - especially in PIK3CA, the gene that encodes the PI3K $\alpha$ catalytic subunit - sensitize tumors to this strategy. Furthermore, the optimal combinations of endocrine agents and PI3K pathway inhibitors have not been established and the strategy for patients with estrogen deprivation (aromatase inhibitor)-resistant disease is unclear. Finally, a question has recently arisen regarding the relevance of the common PIK3CA mutation as a therapeutic target since several reports have suggested that PIK3CA mutation is associated with a favorable prognosis $[6,7]$. If this is the case, PIK3CA mutations would be expected to be rare in advanced disease and therefore less relevant as a therapeutic target in this setting.

To address these issues, a panel of ER-positive breast cancer cell lines with different PI3K pathway mutations were tested against three different PI3K pathway inhibitors, with selectivity against either the rapamycin-sensitive mammalian target of rapamycin (mTOR) complex (Everolimus/RAD001), the PI3K catalytic isoforms
(BKM120) or both PI3K and mTOR (BGT226) in the presence or absence of estrogen or ER downregulation by fulvestrant. In addition, these inhibitor combinations were retested after the development of long-term estrogen deprivation (LTED) resistance to model-acquired resistance to estrogen deprivation. PIK3CA mutation analysis was performed on tumor biopsies from recurrent disease and in patients with stage 4 breast cancer to determine the prevalence of mutations in advanced disease and to correlate mutation status with the rate of tumor progression and death.

\section{Materials and methods Pharmacological agents}

BGT226, BKM120 and RAD001 were obtained through material transfer agreements with Novartis (Basle, Switzerland). Fulvestrant (Sigma-Aldrich, St. Louis, MO, USA), LY294002 (Enzo Life Sciences, Plymouth Meeting, PA, USA), rapamycin (Enzo Life Sciences) and $17 \beta$-estradiol (Sigma-Aldrich) were from commercial sources. $17 \beta$-Estradiol was dissolved in ethanol; inhibitors were dissolved in dimethylsulfoxide.

\section{Cell culture}

The HCC712 cell line [8] was kindly provided by Dr Adi Gazdar. Other cell lines were obtained from American Type Culture Collection (Manassas, VA, USA). Experiments with parental cell lines were performed with low-passage-number cells used within 2 to 3 months following revival from the supplier. Cell lines were propagated in RPM1 1640 containing 10\% fetal bovine serum (FBS) with antibiotic and supplements $(50 \mu \mathrm{g} / \mathrm{ml}$ gentamycin, pyruvate, $10 \mathrm{mM}$ Hepes and glucose to $4.5 \mathrm{~g} / \mathrm{l}$ ) in a humidified $37^{\circ} \mathrm{C}$ incubator containing $5 \%$ carbon dioxide. LTED MCF7 and T47D cell line variants were produced by culturing the parental lines for $>9$ months in phenol-red-free RPMI 1640 containing 5\% charcoalstripped FBS (charcoal-stripped serum (CSS); Invitrogen, Carlsbad, CA, USA) containing antibiotic and supplements (CSS medium). Estrogen-retreated LTED sublines (LTED-R cells) were created by treating LTED cells growing in CSS medium with $10 \mathrm{nmol} / \mathrm{l} 17 \beta$-estradiol for at least 4 months prior to experiments. For studies using short-term estrogen deprivation (STED) parental cell lines, cells were maintained in CSS medium for 1 to 3 weeks prior to experimental treatments.

\section{Protein extraction}

For pharmacological treatments, cells were deprived of serum for 3 to 4 hours, pretreated with the indicated agents for 20 minutes, and then treated with or without $20 \%$ FBS for 15 minutes. Lysates were prepared by extracting cells in lysis buffer as previously described [5]. 


\section{Immunoblotting}

Extracted proteins were analyzed by immunoblotting as previously described [5] using primary antibodies and appropriate horseradish peroxidase-conjugated secondary antibodies (1:20,000; Jackson Immmunoresearch Laboratories, West Grove, PA). Primary antibodies for immunodetection included: ER (RM-9101; Fisher Scientific, Fremont, CA, USA), human epidermal growth factor receptor 2 (HER2) (\#A0485; Dako, Carpenteria, CA, USA), phospho-Y1248-HER2 (\#M7269; Dako), p110 (ab1678; AbCam, Cambridge, MA, USA) and actin (sc1616; Santa Cruz Biotechnology, Santa Cruz, CA, USA). Antibodies for detecting p110 $\alpha$ (\#4249), p110ß (\#3011), p110 (\#4252), phosphatase and tensin homolog (PTEN) (\#9559), Akt1 (\#2938), Akt2 (\#2964), Akt3 (\#3788), phospho-Ser473 Akt (p-Akt) (\#4060), mTOR (\#2983), S6 protein kinase 1 (\#2708), phospho-Thr 389-S6 protein kinase 1 (\#9206), S6 (\#2217), phospho-Ser235/236 S6 (p-S6) (\#4856), p44/42 mitogen-activated protein kinase (MAPK; ERK1/2) (\#4695) and phospho-Thr202/ Tyr204 p44/42 MAPK (p-ERK1/2) were from Cell Signaling Technology (Danvers, MA, USA).

\section{Cell growth assay and calculation of $50 \%$ inhibitory/lethal concentrations}

To determine the effects of estradiol and fulvestrant on the growth of LTED cells, the cells growing in CSS medium were plated in 96-well Optilux dishes and were treated without or with fulvestrant $(300 \mathrm{nmol} / \mathrm{l})$ or the indicated concentrations of $17 \beta$-estradiol on the day after plating. The medium was replenished every 3 to 4 days and cell growth was assessed after 7 days by measuring Alamar Blue reduction $\left(555 \lambda_{\mathrm{Ex}} / 585 \lambda_{\mathrm{Em}}\right)$ with a fluorescent microplate reader. For calculation of the half maximal inhibitory concentration $\left(\mathrm{IC}_{50}\right)$ and the $50 \%$ lethal concentration $\left(\mathrm{LC}_{50}\right)$, cells were cultured in phenol-red-free RPM1 1640 containing 5\% CSS (CSS medium) for at least 1 week prior to plating in 96-well Optilux dishes $(\sim 1,000$ to 3,000 cells/well per given cell line) for drug treatment. Alternatively, cells growing in phenol red RPMI 1640 medium containing 10\% FBS were plated in 96-well Optilux dishes and then switched to CSS medium for at least 1 week prior to drug treatment. Five dilutions of each drug were made using a 1:5 serial dilution. Treatments were performed in triplicate and the experiments in each cell line were performed at least twice. The effect of treatments on cell viability were assessed 0 hours (at the time of drug addition) and 96 hours after drug exposure by measuring the Alamar Blue reduction $\left(555 \lambda_{E x} / 585 \lambda_{E m}\right)$ using a fluorescent microplate reader. Cell growth was analyzed using GraphPad Prism version 5.00 for Windows (GraphPad
Software, San Diego, CA, USA). The fitted curves were then used to determine the $\mathrm{IC}_{50}$ and $\mathrm{LC}_{50}$ values.

\section{Apoptosis assay}

To quantify apoptosis, cells growing in CSS medium were treated as indicated for 4 days. For treatments using fulvestrant, cells were pretreated with fulvestrant for 3 days prior to treatment with estradiol or PI3K inhibitors to ensure sufficient downregulation of the ER. Floating and adherent cells were then collected and labeled to detect apoptotic cells using the APO-BrdU TUNEL Assay Kit (Invitrogen) in accordance with the manufacturer's instructions. For each sample, a minimum of 10,000 events were acquired on a Cytomics FC500 flow cytometer (Becton Dickinson, Fremont, CA, USA) and data were analyzed using FlowJo software (Tree Star, Ashland, OR, USA).

\section{Patient samples}

Human tumor samples from patients with recurrent or metastatic breast cancer were obtained under the auspices of an Institutional Review Board-approved protocol at the Siteman Cancer Center at Barnes-Jewish Hospital and Washington University School of Medicine between January 2004 and January 2009. Informed consent was obtained from all patients involved. Information on ER, progesterone receptor and HER2 at initial and recurrent diagnosis was obtained from patient pathological reports. Preparation of samples for tumor DNA extraction and resequencing of PIK3CA exons 9 and 20 using genomic DNA was performed as described previously [5].

\section{Statistical analysis}

Unless indicated otherwise, quantitative data for in vitro studies are presented as the mean \pm standard deviation. The effect of pharmacologic treatments on apoptosis was analyzed using analysis of variance, and post-hoc multiple comparisons were performed between specific treatments if the overall difference reached statistical significance $(P<0.05)$. The relationship between PIK3CA mutation and other covariates was performed using Fisher's exact test or Student's $t$ test as appropriate. Overall survival was defined as the time from diagnosis to the date of death due to any cause. Survivors were censored at the date of last contact. Disease-free survival was only calculated in subjects with an initial stage of I to III and was defined as the time from diagnosis to the first recurrence or death. The overall survival and disease-free survival across mutation status were estimated using the Kaplan-Meier product limit method and were compared by log-rank test. All analyses were 
two-sided and significance was set at $P<0.05$. Statistical analyses were performed using SAS software (SAS Institute, Cary, NC, USA).

\section{Results}

Expression and activation of PI3K pathway proteins in breast cancer cells

To assess PI3K signaling activity in the panel of breast cancer cells used for the present investigation, the levels of phosphorylated forms of AKT, S6 protein kinase 1 and S6 (indicators of PI3K signaling activation), and the expression of PI3K catalytic subunit isoforms, PTEN, AKT isoforms and mTOR were examined (Figure 1). The panel included ER-positive breast cancer cells with activating PIK3CA mutations (helical domain mutation: MCF7 and BT-483; kinase domain mutation: T47D), PTEN mutation (MDA-MB-415, ZR75-1 and CAMA-1), HER2 gene amplification (HCC1419) or wild-type PIK3CA and PTEN (HCC712, HCC1428, HCC1500 and MDA-MB-175), and ER-negative breast cancer cell lines with HER2 amplification (SK-BR-3), and wild-type PIK3CA and PTEN (HCC1806). The ERnegative MDA-MB-231 cell line is wild-type for PIK3CA and PTEN but harbors mutations in K-RAS and B-RAF.

While the PI3K $\mathrm{p} 110 \alpha$ and $\mathrm{p} 110 \beta$ catalytic subunits were present in all cell lines, the PI3K p110 $\delta$ and p110 $\gamma$ catalytic subunits were significantly expressed only in ER-negative (SK-BR-3, HCC1806 and MDA-MB-231) cell lines. Akt1 and Akt2 were expressed in all tested breast cancer cell lines, but Akt 3 was detectable only in MDA-MB-231 cells [9]. Consistent with previous studies, high levels of p-Akt were present in cells with PIK3CA kinase domain mutation (T47D), PTEN mutation (MDA-MB-415, ZR75-1 and CAMA-1), HER2 amplification (HCC1419, SK-BR-3) [9-11] and the heregulin-dependent MDA-MB-175 cell line. Phosphorylation of the PI3K downstream target S6 closely paralleled Akt phosphorylation.

These data indicate that mutations in PIK3CA and PTEN or amplification of HER2 are associated with PI3K pathway activation in breast cancer.

\section{BGT226, BKM120 and RAD001 inhibit PI3K pathway} signaling in breast cancer cells

There are at least four general subcategories of PI3K pathway inhibitors, based upon target specificity, that are currently in clinical use or in various phases of clinical testing. These include inhibitors of PI3K catalytic subunits; inhibitors of the Akt serine-threonine kinase; inhibitors of mTOR; and multi-targeted agents, which typically have dual-specificity PI3K and mTOR kinase inhibitors [12]. This paper focuses on three of these four classes of agent: RAD001 (inhibitor against rapamycin-sensitive

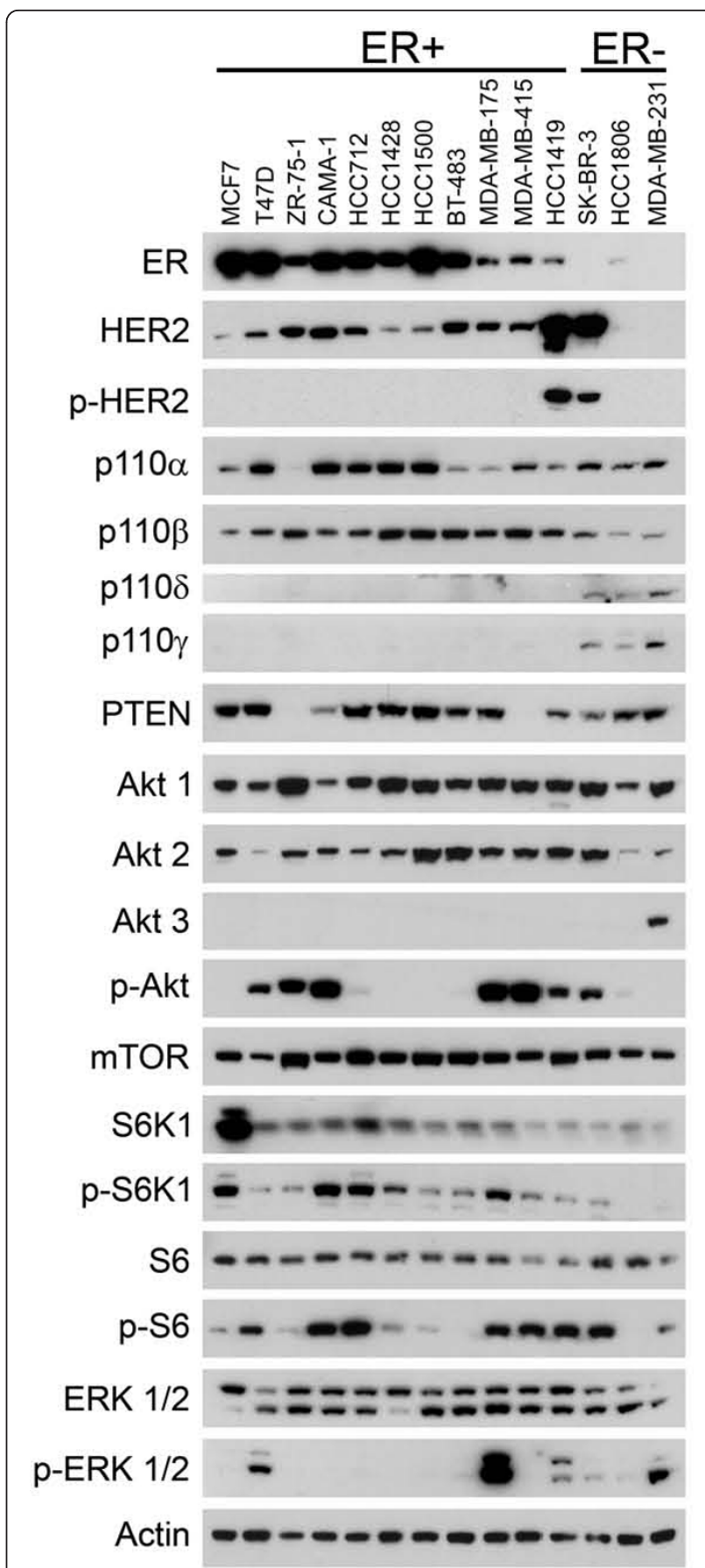

Figure 1 Analysis of phosphatidylinositol-3-kinase pathway signaling in breast cancer cells. Cell lines were grown to subconfluency and placed in medium containing low (0.5\%) fetal bovine serum overnight prior to preparation of cell lysates. Equal amounts $(25 \mu \mathrm{g})$ of extracted protein from each cell line were then immunoblotted using antibodies against the indicated proteins. PTyr1248 HER2 ( $p$-HER2); p-Ser473 Akt ( $p$-Akt); $p$-Thr389 S6 protein kinase 1 ( $p$-S6K1); p-Ser235/236 S6 (p-S6); p-Thr202/Tyr204 ERK ( $p$ ERK). ER, estrogen receptor; HER2, human epidermal growth factor receptor 2; PTEN, phosphatase and tensin homolog; mTOR, mammalian target of rapamycin. 
mTOR complex), BKM120 (inhibitor against PI3K catalytic isoforms) and BGT226 (dual inhibitor of PI3K/ mTOR).

To illustrate the inhibitory activities of BGT226, BKM120 and RAD001 on PI3K pathway signaling, the phosphorylation levels of Akt (p-Akt) and S6 (p-S6) were assessed by western blotting in MDA-MB-231,
MCF7, T47D, or HCC712 cell lines in the presence of increasing dose of drug. As expected, BGT226 and BKM120 inhibited the phosphorylation of both Akt and S6 in all tested lines (Figure 2a,b). BGT226 treatment produced almost complete inhibition of PI3K signaling at low nanomolar $(50 \mathrm{nmol} / \mathrm{l})$ concentrations, indicating a similar, or greater, potency compared with that of the

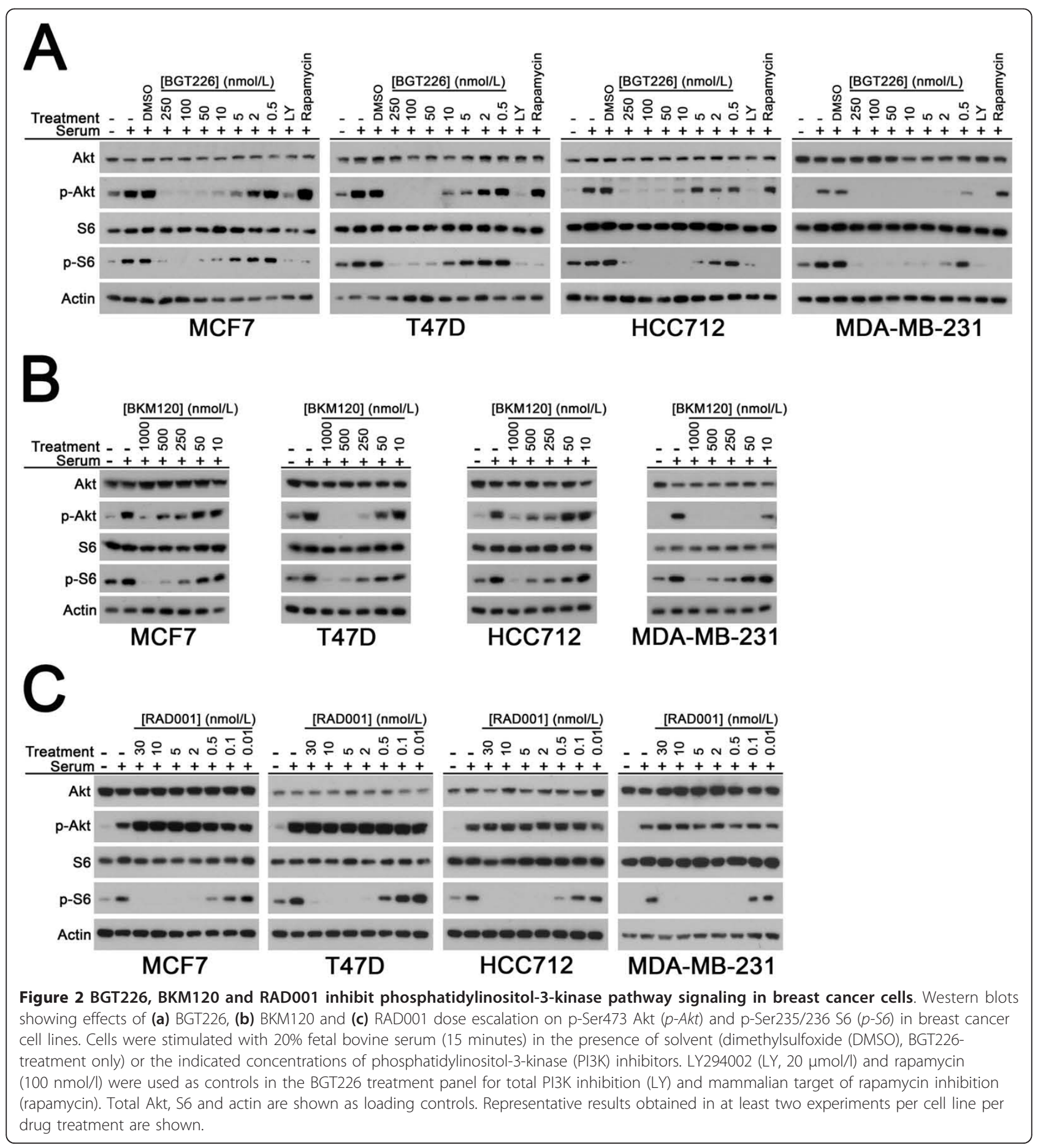


dual PI3K/mTOR inhibitor BEZ235 $[5,13,14]$. In contrast, significant inhibition of PI3K signaling following BKM120 treatment occurred in the mid-nanomolar to high-nanomolar concentration range (250 to 1,000 $\mathrm{nmol} / \mathrm{l})$ in most cell lines. In all cell lines, RAD001 treatment completely inhibited S6 phosphorylation at low nanomolar $(5 \mathrm{nmol} / \mathrm{l})$ concentrations, with the paradoxical increase in Akt phosphorylation MCF7 cells already noted by other investigators (Figure 2c) [14-16].

These data indicate that PI3K pathway inhibitors effectively suppressed their respective targets regardless of individual differences in PI3K pathway mutation status.

\section{PIK3CA mutation sensitizes short-term estrogen-deprived} ER-positive breast cancer cells to PI3K pathway inhibitors To extend our previous observations regarding the sensitizing effect of estrogen deprivation on the apoptotic effect of PI3K pathway inhibitors in ER-positive breast cancer [5], a larger panel of ER-positive breast cancer cell lines was examined that varied with respect to PIK3CA and PTEN mutation status (Figure 3). Cells in the panel were acutely deprived of estrogen for 1 to 3 weeks prior to treatment with BGT226, BKM120 or RAD001 at concentrations that were found to be sufficient to abrogate pathway signaling (Figure 2a to 2c). The MDA-MB-231 line served as a control for off-target inhibitor effects since this line does not undergo apoptosis when treated with the dual PI3K/mTOR inhibitor BEZ235 [5,17] or combined siRNA knockdown of PIK3CA and PIK3CB [5].

Induction of apoptosis was measured by TUNEL assay after treatment with BGT226 (50 nmol/l), BKM120 $(1 \mu \mathrm{mol} / \mathrm{l})$ or RAD001 (30 nmol/l) (Figure 3a to $2 \mathrm{c}$ ). In the absence of estrogen, BGT226 treatment induced the highest levels of apoptosis, followed by BKM120, whereas RAD001 treatment produced only a modest increase in apoptosis in a few cell lines (Figure 3a to 2c), suggesting this class of agent may be a relatively ineffective partner for endocrine therapy combinations. Importantly, we observed that the induction of high levels of apoptosis by both BGT226 and BKM120 was restricted to PIK3CA mutant lines (MCF7, T47D and $\mathrm{BT}-483)$ and the PTEN-negative MDA-MB-415 and ZR75-1 cell lines. BGT226 treatment also produced a significant but modest increase in apoptosis in the HCC1428 line (wild-type PIK3CA and PTEN) and the PIK3CB-amplified HCC712 cell line, compatible with this agent having the broadest inhibitory activity. Sensitivity to PI3K pathway inhibition and the presence of a pathway mutation, however, were not linked in all lines because PTEN mutant CAMA-1 cells were resistant to BGT226 and BKM120 (Figure 3a,b) despite effective inhibition of PI3K pathway signaling (data not shown).
Interestingly, the absence of ERK1/2 phosphorylation (Figure 1) in CAMA-1 argues against the activation of the ERK pathway as a mechanism of resistance. The effect of RAD001 on apoptosis was modest overall, but two of the three cell lines in which RAD001 induced apoptosis (MCF7, BT-483) contain PIK3CA helical domain mutations.

Taken together, these data indicate that dual PI3K/ mTOR and PI3K isoform inhibitors are likely to produce the greatest effects in ER-positive breast cancer, particularly in tumors harboring PIK3CA mutation and, possibly, PTEN loss.

As a complementary approach for measuring relative drug sensitivity, the $\mathrm{IC}_{50}$ and $\mathrm{LC}_{50}$ values were calculated for all three inhibitors in the cell line panel under estrogen-deprived conditions (Table 1). Consistent with TUNEL assay results, $\mathrm{LC}_{50}$ values in the low nanomolar per liter range were obtained in the PTEN-negative MDA-MB-415 and ZR75-1 lines and in the three PIK3CA mutant (MCF7, T47D, BT-483) cell lines. The $\mathrm{LC}_{50}$ values for BKM120 were higher than for BGT226, which is consistent with the higher concentration of BKM120 needed to inhibit PI3K signaling in cell lines (Figure 2b). As expected, BKM120-sensitive cell lines identified by TUNEL generally exhibited lower $\mathrm{LC}_{50}$ values. Although the $\mathrm{LC}_{50}$ value for $\mathrm{RAD} 001$ was attained in HCC1428 cells, we did not observe any induction of apoptosis by TUNEL assay (Figure 3c). Regardless, the data for $\mathrm{IC}_{50}$ and $\mathrm{LC}_{50}$ were mostly consistent with results obtained from TUNEL assays.

Estradiol inhibits BGT226 and BKM120 treatment-induced apoptosis but in a cell-line-dependent manner

We have previously shown that estradiol significantly suppressed the induction of apoptosis by inhibition of p $110 \alpha$ and $p 110 \beta$ by RNA interference or treatment with the dual PI3K/mTOR inhibitor BEZ235 in ER-positive MCF7, T47D and HCC712 cells [5]. To determine whether estradiol broadly inhibits apoptosis induced by other PI3K inhibitors and in other ER-positive cell lines, the effect of BGT226 was compared in the presence and absence of estradiol. While estradiol suppressed BGT226induced apoptosis in STED MCF7 and T47D cells, estradiol had no effect on PI3K inhibitor-induced apoptosis in BT483, MDA-MB-415 and ZR75-1 cells (Figure 4a). Treatment with estradiol induced proliferation in these lines, however, suggesting that the ER was functional ([5] and data not shown). Dose escalation of BGT226 (Figure 4b) and BKM120 (Figure 4c) in MCF7 and T47D cells demonstrated that inhibition of cell death by estradiol was progressively lost at higher PI3K inhibitor concentrations. The modest increase in apoptosis with RAD001 treatment in STED MCF7 cells (Figure 3c) was also suppressed by estradiol (data not shown). 


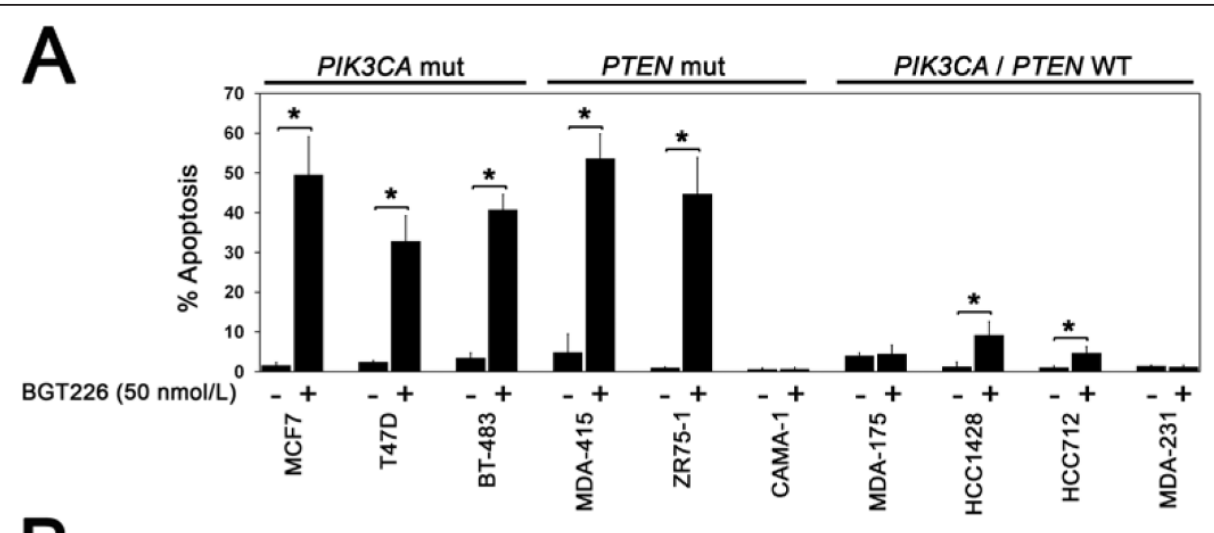

B

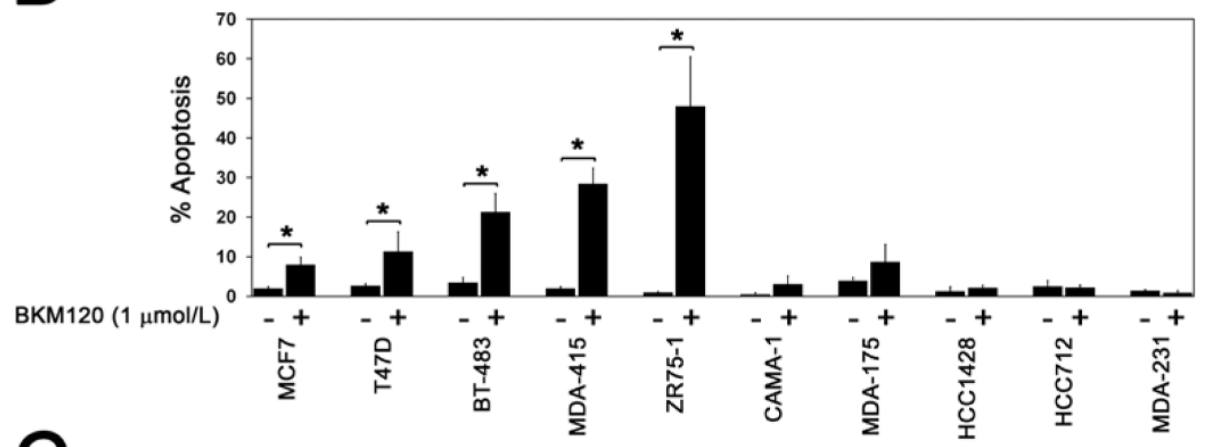

C

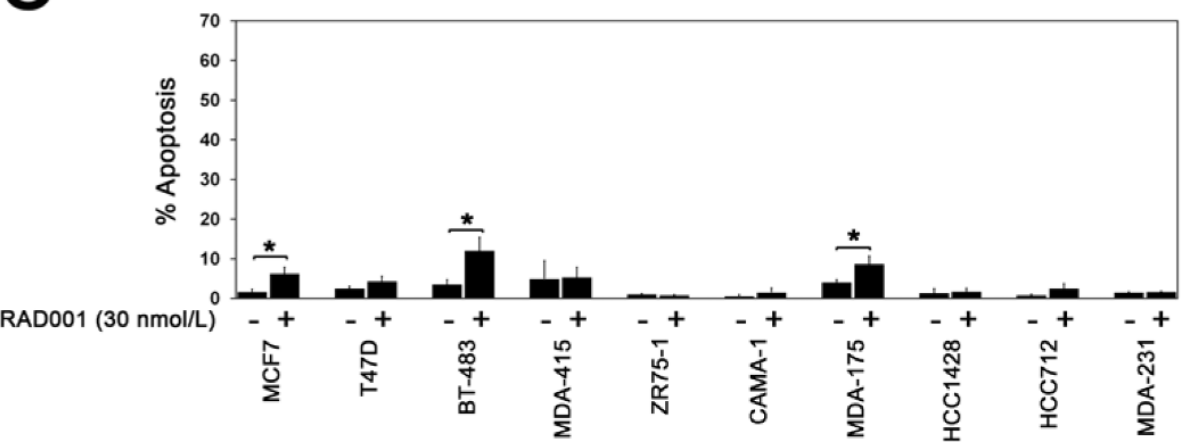

Figure 3 PIK3CA mutation and phosphatase and tensin homolog loss confer sensitivity to phosphatidylinositol-3-kinase pathway inhibitors. PIK3CA mutation and phosphatase and tensin homolog (PTEN) loss confer sensitivity to phosphatidylinositol-3-kinase pathway inhibitors in estrogen-deprived estrogen-receptor-positive breast cancer cells. Cells cultured under estrogen-deprived conditions were treated

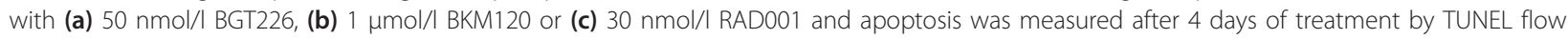
cytometry. Results are from at least three replicates for each treatment condition per cell line. Significant induction of apoptosis by treatment with inhibitors is indicated $(* P<0.05)$. WT, wild-type.

Overall, these data suggest estradiol-induced resistance is a shared characteristic across all three classes of PI3K pathway inhibitors tested, but there is marked heterogeneity in the inhibitory effect of estradiol across ER-positive breast cancer cell lines.

\section{BGT226, BKM120 and RAD001 inhibit PI3K pathway} signaling despite long-term estrogen deprivation

To model the effects of PI3K pathway inhibition in aromatase-inhibitor-resistant breast cancer cells, variants of the MCF7 and T47D lines were generated through
LTED by over 9 months of culture in low-estrogen conditions (Figure 5a). ER upregulation and increased phosphorylation of Akt, S6 and the MAPK/ERKs (p-ERK) was observed in MCF7 LTED cells compared with the parental line. In the T47D LTED line, S6 and ERK phosphorylation, but not p-Akt, was higher than in parental T47D cells, and ER expression was downregulated to undetectable levels.

Both LTED lines were subsequently retreated with estradiol $(10 \mathrm{nmol} / \mathrm{l})$ for at least 4 months to determine whether estradiol re-exposure could reverse the signaling 
Table 1 Determination of LC $_{50}$ and IC 50 values for BGT226, BKM120 and RAD001 in breast cancer cells

\begin{tabular}{|c|c|c|c|c|c|c|c|c|}
\hline \multirow[t]{2}{*}{ Cell line } & \multirow[t]{2}{*}{ ER status } & \multirow[t]{2}{*}{ Genotype } & \multicolumn{2}{|c|}{ BGT226 (nmol/l) } & \multicolumn{2}{|c|}{ BKM120 (nmol/l) } & \multicolumn{2}{|c|}{ RAD001 (nmol/l) } \\
\hline & & & $\mathrm{LC}_{50}$ & $\mathrm{IC} \mathrm{C}_{50}$ & $\mathrm{LC}_{50}$ & $\mathrm{IC} \mathrm{C}_{50}$ & $\mathrm{LC}_{50}$ & $\mathrm{IC} \mathrm{C}_{50}$ \\
\hline MCF7 & Positive & PIK3CA E545K & 7.5 & 3.5 & 3,981 & 248 & $>625$ & $>625$ \\
\hline T47D & Positive & PIK3CA H1047R & 10 & 2.7 & 316 & 128 & $>625$ & 1.5 \\
\hline HCC712 & Positive & PIK3CB amp & 549 & $>625$ & $>10,000$ & 347 & $>625$ & $>625$ \\
\hline MCF7 LTED & Positive & PIK3CA E545K & 398 & 1.18 & 2,691 & 70.7 & $>625$ & $<1$ \\
\hline MCF7 LTED-R & Positive & PIK3CA E545K & 617 & 5.1 & $>10,000$ & 4,926 & $>625$ & $>625$ \\
\hline T47D LTED & Negative $^{a}$ & PIK3CA H1047R & 19 & 2.3 & 630 & 243 & $>625$ & $<1$ \\
\hline BT-483 & Positive & PIK3CA E542K & 2.5 & 7.05 & $>10,000$ & $>10,000$ & $>625$ & $<1$ \\
\hline MDA-MB-415 & Positive & PTEN mut & 28.1 & $<1$ & 1,584 & 1,294 & $>625$ & $>625$ \\
\hline CAMA-1 & Positive & PTEN mut & 275 & 46.2 & $>10,000$ & $>10,000$ & $>625$ & $<1$ \\
\hline ZR75-1 & Positive & PTEN mut & 1.3 & $<1$ & 363 & 207 & $>625$ & $<1$ \\
\hline HCC1428 & Positive & PIK3CA/PTEN wt & 501 & $>625$ & 1,258 & 1,138 & 3.1 & $<1$ \\
\hline MDA-MB-175 & Positive & PIK3CA/PTEN wt & $>625$ & $<1$ & 5,011 & $>10,000$ & $>625$ & $<1$ \\
\hline MDA-MB-231 & Negative & K-Ras, B-Raf mut & $>625$ & $<1$ & $>10,000$ & 1,237 & $>625$ & $>625$ \\
\hline
\end{tabular}

Cell lines growing under estrogen-deprived conditions in CSS medium were incubated with solvent control or increasing concentrations of the indicated compounds and cell viability was assessed at 0 hours (time of drug addition) and at 96 hours after treatment. PIK3CA, PIK3CB and PTEN mutation information has been published previously $[5,22]$ or was obtained from the Sanger website [31]. ER, estrogen receptor; $\mathrm{IC}_{50}$, half maximal inhibitory concentration; $\mathrm{LC}_{50}$, $50 \%$ lethal concentration; mut, mutant; wt, wild-type. ${ }^{\mathrm{a} E R}$ was not detectable by western blot.

effects associated with LTED. In the resulting MCF7 revertant subline (MCF7 LTED-R), ER expression and levels of p-Akt, p-S6 and p-ERKs were downregulated to similar levels observed in the parental MCF7 cells, indicating that prolonged estradiol re-exposure reversed the effects of LTED on these proteins. In contrast, while S6 and ERK phosphorylation were downregulated by estradiol in T47D LTED-R cells, ER expression levels were not restored - at least not to a level detectable by western blot. The effect of the three PI3K pathway inhibitors on signal transduction demonstrated that the dose-response relationships for all three agents were similar to those observed in the parental MCF7 and T47D cell lines (Figure 5b). The sensitivity of the LTED lines to estradiol and fulvestrant was also determined. As expected, proliferation of MCF7 LTED and T47D LTED cells was not enhanced by increasing concentrations of estradiol (Figure 5c,d). Indeed the MCF7 LTED model was paradoxically inhibited by estradiol because 10 nmol/l treatment for $>10$ days inhibited growth and induced cell death $[18,19]$ (data not shown). Treatment of estrogen-deprived MCF7 LTED with the ER-selective inhibitor fulvestrant [20] inhibited the growth of cells, demonstrating that ER remains functionally important for the growth of these cells despite the absence of supplemental estradiol. In contrast, treatment with estradiol or fulvestrant did not have significant effects on the growth of ERnegative T47D LTED cells (Figure 5d).

\section{Long-term estrogen-deprived cells are resistant to the induction of apoptosis by low-dose PI3K pathway inhibitors}

To determine the effect of LTED on PI3K drug sensitivity, we compared the ability of BGT226 and BKM120 to induce apoptosis in STED and LTED cell line pairs. In comparison with MCF7 and T47D STED cells, higher drug concentrations were required for both BGT226 (Figure 6a) and BKM120 (Figure 6b) to induce significant apoptosis under LTED conditions. The $\mathrm{LC}_{50}$ values for BGT226 in both LTED lines, and for BKM120 in T47D LTED cells, were consistent with resistance to apoptosis measured by TUNEL (Table 1). At the highest doses of BKM120 and BGT226 tested, however, T47D LTED cells were more sensitive than STED T47D cells; this pattern was not replicated in MCF7 LTED cells, where resistance to BGT226 persisted at all of the doses tested.

Despite resistance to the proliferative effects of estradiol, acute treatment with estradiol suppressed apoptosis induced by BGT226 and BKM120 treatment in MCF7 LTED cells -indicating that the survival effects of estradiol were decoupled from mitogenic effects (Figure 6c). In contrast, estradiol did not suppress BGT226-induced or BKM120-induced apoptosis in ER-negative T47D LTED cells.

\section{Treatment with fulvestrant sensitizes MCF7 LTED cells to PI3K inhibition}

To model options for patients with disease progression on aromatase inhibitor treatment, the effect of fulvestrant was studied in LTED lines. Fulvestrant alone did not promote apoptosis in STED cells or LTED cells (Figure 7a,b); fulvestrant strongly potentiated apoptosis when combined with BGT226, BKM120 and RAD001 treatment in MCF7 LTED cells, however, confirming that ligand-independent ER activity promoted PI3K inhibitor resistance (Figure 7a). In contrast, treatment with 


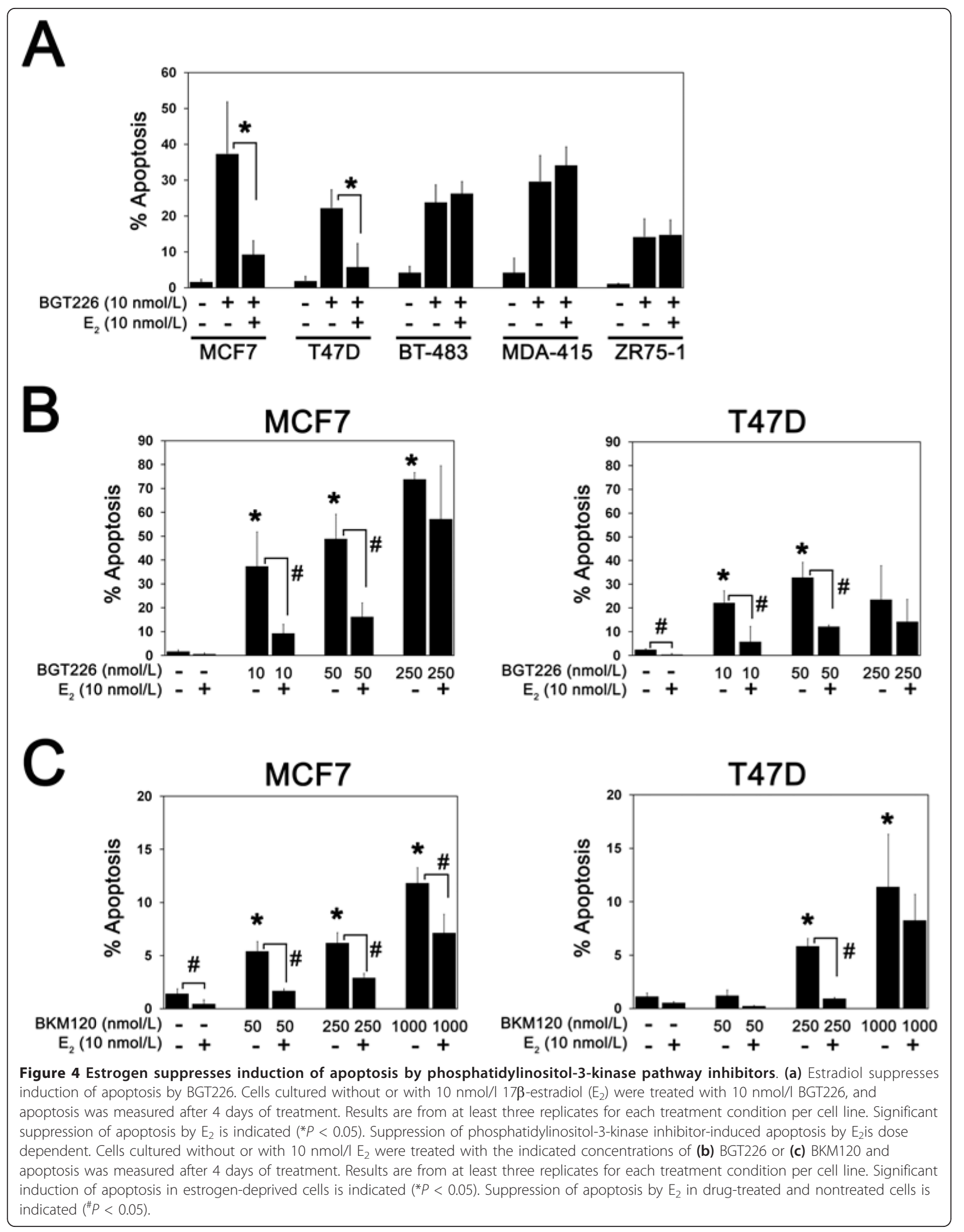




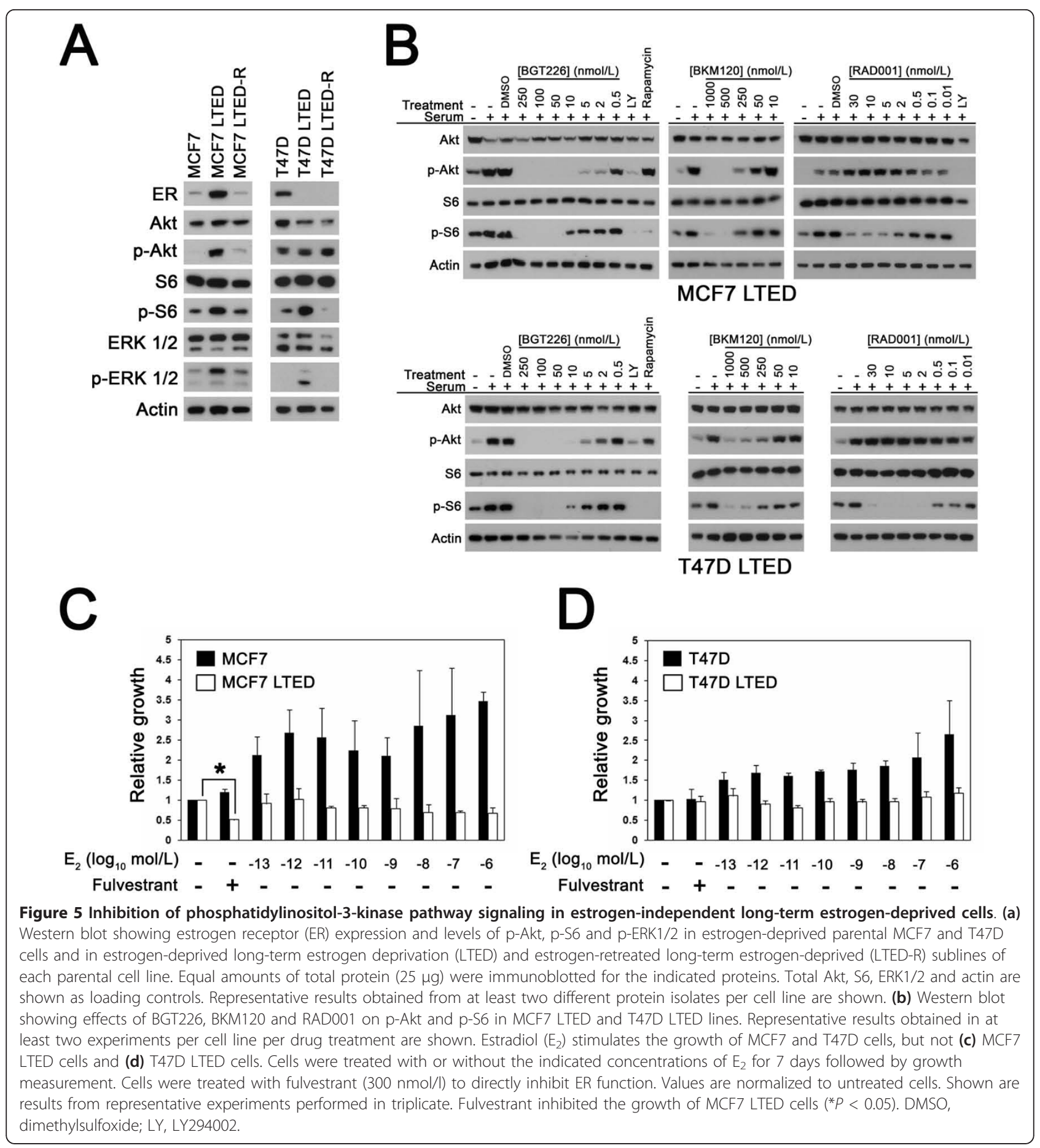

fulvestrant did not promote apoptosis in the ER-negative T47D LTED cells with any of the three agents tested.

Taken together, these data suggest that fulvestrant may sensitize cells to the therapeutic effects of PI3K inhibitors under circumstances where resistance to estrogen deprivation is associated with ligand-independent ER activity.
Prolonged retreatment with estradiol re-sensitizes MCF7 LTED cells to PI3K inhibition

As an alternative to fulvestrant, breast cancer patients with advanced ER-positive aromatase-inhibitor-resistant disease can be treated with low-dose estradiol to induce tumor regression and, in some instances, resensitize the patients' tumor to estrogen deprivation therapy with an 


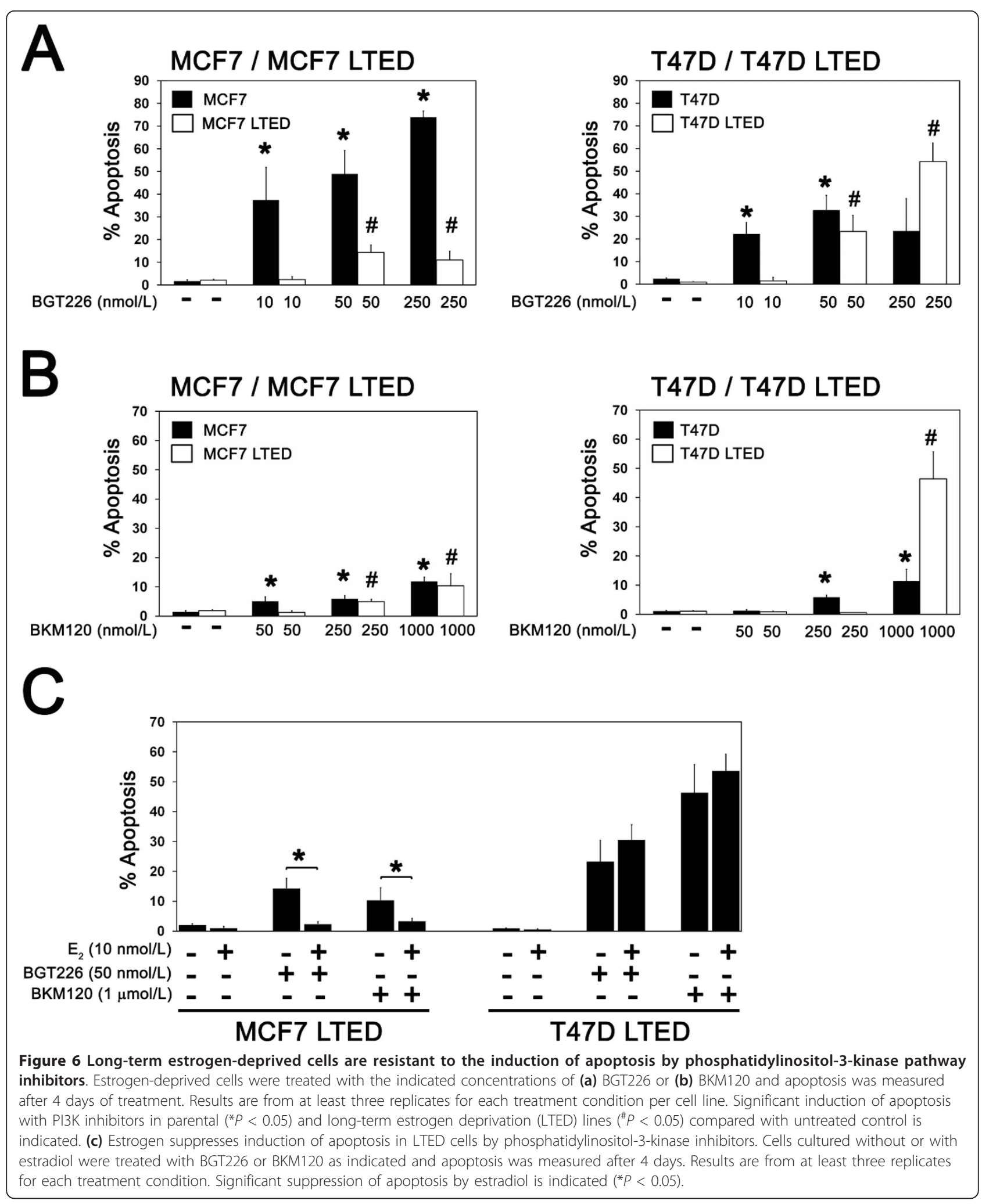




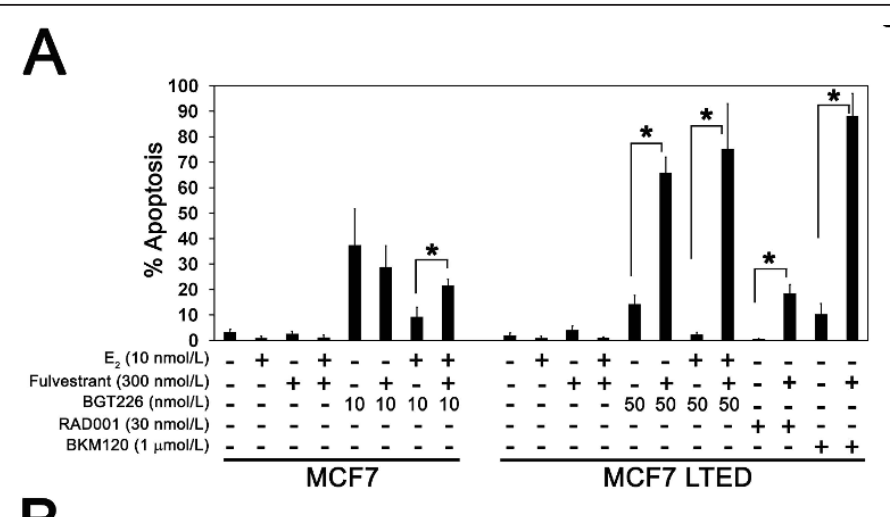

B

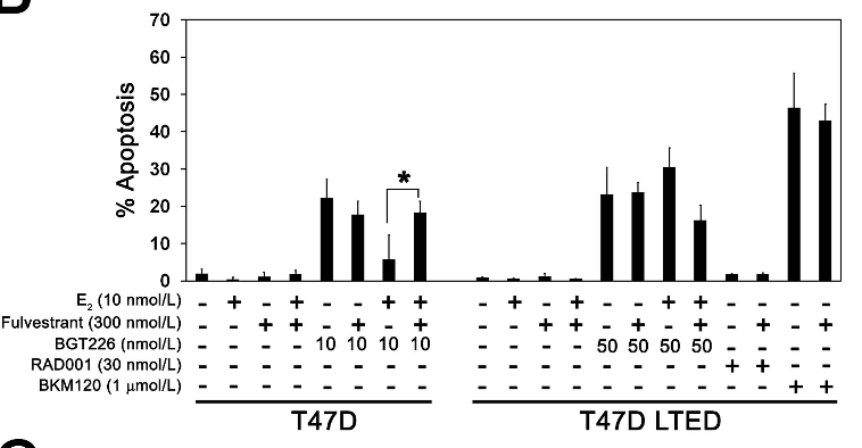

C

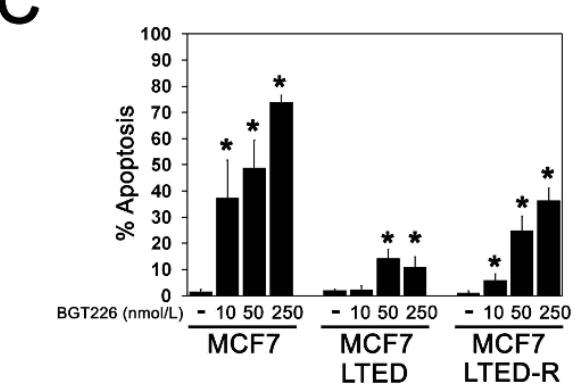

D

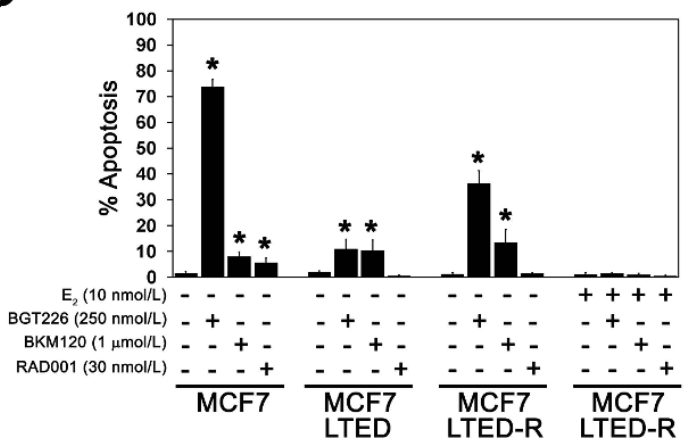

Figure 7 Fulvestrant and estradiol treatment sensitize long-term estrogen-deprived cells to phosphatidylinositol-3-kinase inhibitors. Estrogen-deprived (a) MCF7 and MCF7 long-term estrogen deprivation (LTED) cells or (b) T47D and T47D LTED cells were treated with fulvestrant, estradiol $\left(E_{2}\right)$ or phosphatidylinositol-3-kinase (PI3K) pathway inhibitors as indicated and apoptosis was measured after 4 days of treatment. Results are from at least three replicates for each treatment condition. Abrogation of $\mathrm{E}_{2}$ rescue or potentiation of PI3K inhibitorinduced apoptosis by fulvestrant is indicated $(* P<0.05)$. (c) Estrogen-deprived MCF7, MCF7 LTED and MCF7 estrogen-retreated long-term estrogen-deprived (LTED-R) cells were treated with the indicated concentrations of BGT226 and apoptosis was measured after 4 days of treatment. Results are from at least three replicates for each treatment condition. Significant activation of apoptosis is indicated $(* P<0.05)$. (d) MCF7, MCF7 LTED and MCF7 LTED-R cells were treated with $E_{2}$, BGT226, BKM120 or RAD001 as indicated and apoptosis was measured after 4 days. Results are from at least three replicates for each treatment condition. Significant activation of apoptosis with respect to untreated control cells is indicated $\left({ }^{*} P<0.05\right)$. 
aromatase inhibitor [21]. The MCF7 LTED line provides an in vitro parallel of these clinical findings because, when these cells are re-exposed to estradiol, cell growth slows dramatically, followed by a period of recovery during which cell growth once again becomes estrogen dependent (MCF7 LTED-R) (data not shown).

To determine whether MCF7 LTED-R cells also recovered sensitivity to PI3K inhibition, the effects of BGT226, BKM120 and RAD001 treatment were compared between MCF7 LTED-R cells and MCF7 LTED cells (Figure $7 \mathrm{c}, \mathrm{d}$ ). Consistent with partial recovery of sensitivity to PI3K inhibition, lower doses of BGT226 were able to induce apoptosis in estrogen-deprived MCF7 LTED-R cells in comparison with MCF7 LTED cells (Figure 7c). In contrast, the levels of cell death with BKM120 $(1 \mu \mathrm{mol} / \mathrm{l})$ were similar in all three MCF7 cell line variants (Figure 7d) and sensitivity to RAD001 was lost in MCF7 LTED-R cells despite reintroduction of estrogen deprivation.

\section{PIK3CA mutations are common in relapsed ER-positive breast cancer}

The in vitro studies described above suggested that a combination of fulvestrant and a PI3K pathway inhibitor may be an effective approach for aromatase-inhibitorresistant advanced breast cancer, particularly in PI3KCA mutant cases that are persistently ER-positive at relapse. Since PIK3CA mutation has been reported to be associated with a more favorable prognosis [7], however, it was unclear how many patients with ER-positive PIK3CA mutant breast cancer would present with advanced disease. Fresh-frozen research biopsies were therefore obtained from 51 patients with recurrent or metastatic disease for PIK3CA mutation testing (Table 2). Their median age at initial cancer diagnosis was 53.4 (32.3 to 79.9 ) years. The median follow-up was 51.7 (0.9 to 256.7) months. Forty-three out of the $51(84.3 \%)$ patients were deceased at the time of analysis. At initial diagnosis, 32 tumors were ER-positive, 17 tumors were ER-negative, and two tumors were of unknown status. Five out of the 32 ER-positive tumors changed to ER-negative status at recurrence.

PIK3CA mutation analysis was performed on the 27 ER-positive and 24 ER-negative recurrent specimens. We included both ER-positive and ER-negative cases to interrogate the relationship between PIK3CA mutation and ER status in the recurrent disease population. A PIK3CA mutation was identified in 16 of the 51 tumors (31.4\%; eight in the helical domain, eight in the kinase domain), a prevalence similar to that observed in studies that examined primary breast cancer tissue $[6,7,22]$. PIK3CA mutation was strongly associated with ER positivity $(P=0.0076)$. Among the 27 ER-positive tumors,
Table 2 Clinical characteristics of the 51 recurrent or metastatic breast cancers

\begin{tabular}{lll}
\hline Characteristic at initial diagnosis & Number of patients & $\%$ \\
\hline Total & 51 & 100 \\
Median age (years) & $53.4(32$ to 79$)$ & \\
Median follow-up time (months) & $51.7(0.9$ to 256) \\
Stage & 34 & \\
$\quad$ I to III & 17 & 67 \\
$\quad$ IV & 32 & 33 \\
Estrogen receptor & 17 & 63 \\
$\quad$ Positive & 2 & 33 \\
$\quad$ Negative & 4 \\
$\quad$ Missing & 15 & 4 \\
Human epidermal growth factor receptor 2 & 29 \\
$\quad$ Positive & 33 & 65 \\
$\quad$ Negative & 3 & 6 \\
$\quad$ Missing & 16 & 31 \\
PIK3CA mutation & &
\end{tabular}

13 (48\%) were PIK3CA mutant. In contrast, only three of the 24 ER-negative tumors were PIK3CA mutant. ER expression was maintained in 13 out of 14 cases with PIK3CA mutation (Table 3). Consistent with previous reports [7], PIK3CA mutation was associated with a later relapse pattern (disease-free survival $P=0.02$, Figure $8 \mathrm{a}$ ), with a trend for patients with $P I K 3 C A$ mutant disease exhibiting a lower mortality rate (overall survival $P=0.06$, Figure $8 \mathrm{~b})$. In an analysis restricted to patients with initially ER-positive disease, PIK3CA mutant cases still relapsed later than nonmutant cases (disease-free survival $P=0.02$, Figure $8 \mathrm{c}$ ). Survival after relapse in persistently ER-positive tumors (a potentially important endpoint for drug approval), however, was not different between PIK3CA wild-type and mutant cases, although the very small sample size meant that only very large effects could have been detected (Figure 8d).

\section{Table 3 PIK3CA correlation analysis}

\begin{tabular}{|c|c|c|c|c|}
\hline & PIK3CA mutant & PIK3CA wild-type & $n$ & $P$ value \\
\hline \multicolumn{5}{|l|}{ ER at diagnosis } \\
\hline Positive & 14 & 18 & 32 & 0.0082 \\
\hline Negative & 1 & 16 & 17 & \\
\hline \multicolumn{5}{|c|}{ HER2 at diagnosis } \\
\hline Positive & 2 & 13 & 15 & 0.17 \\
\hline Negative & 12 & 21 & 33 & \\
\hline \multicolumn{5}{|c|}{ ER at recurrence } \\
\hline Positive & 13 & 14 & 27 & 0.0076 \\
\hline Negative & 3 & 21 & 24 & \\
\hline \multicolumn{5}{|c|}{ HER2 at recurrence } \\
\hline Positive & 1 & 11 & 12 & 0.79 \\
\hline Negative & 14 & 24 & 38 & \\
\hline
\end{tabular}

ER, estrogen receptor; HER2, human epidermal growth factor receptor 2. 


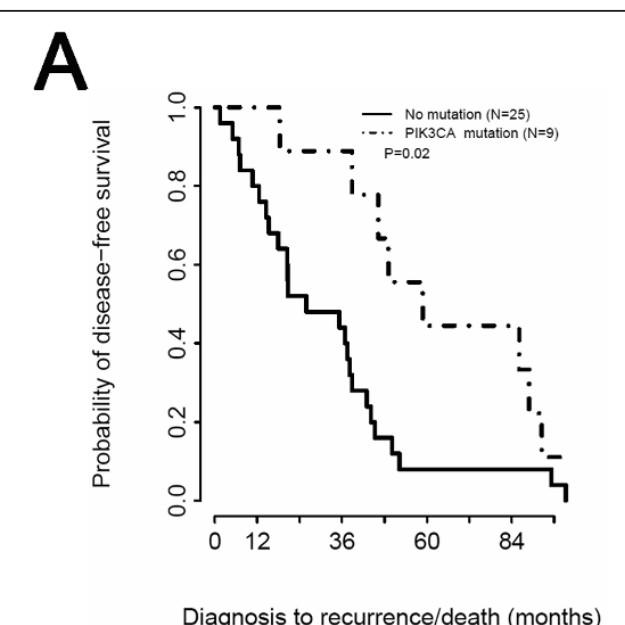

Diagnosis to recurrence/death (months)

\section{C}

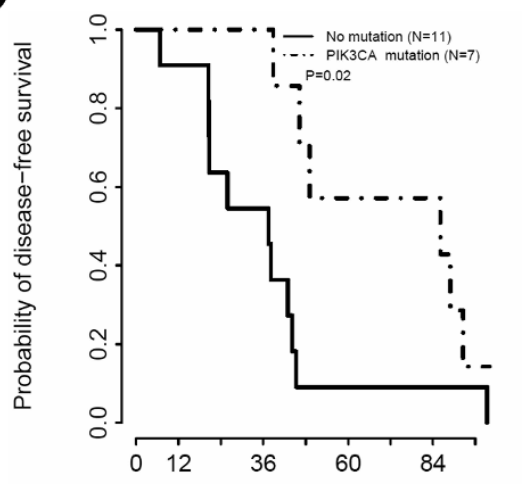

Diagnosis to recurrence/death (months)
B

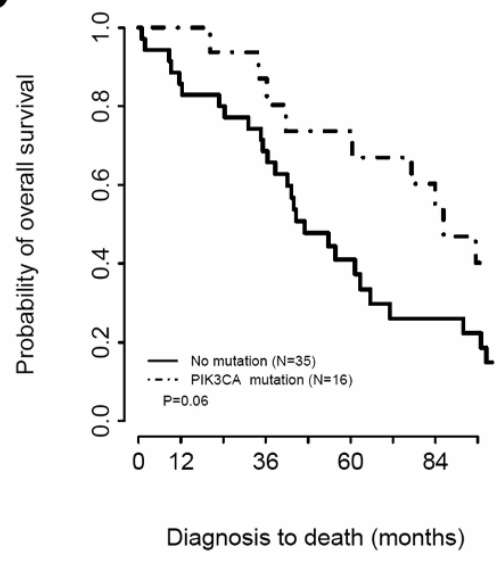

D

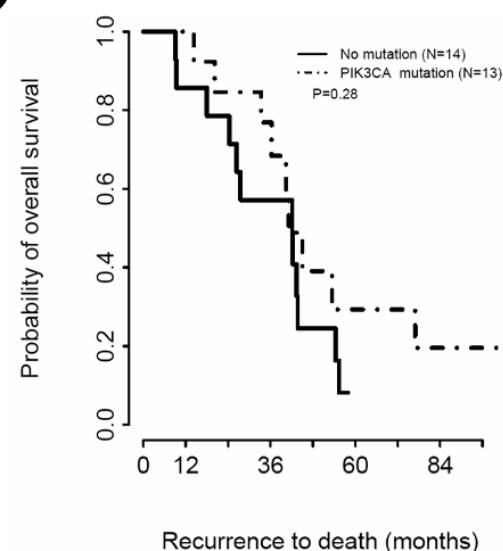

Figure 8 PIK3CA mutation associates with superior disease-free survival. (a) Kaplan-Meier curves for disease-free survival (DFS) based on PIK3CA mutation status in all patients. (b) Kaplan-Meier curves comparing overall survival (OS) in all patients with PIK3CA wild-type and mutant tumors. (c) Kaplan-Meier curves for DFS based on PIK3CA mutation status in patients with estrogen receptor (ER)-positive breast cancer. (d) Kaplan-Meier curves comparing OS in ER-positive breast cancer patients (ER status at time of recurrence) with PIK3CA wild-type and mutant tumors, from the time of relapse.

\section{Discussion}

The primary aim of the present study was to assess the case for combined targeting of ER and PI3K pathway inhibition by examining an extended panel of ER-positive breast cancer cell lines using clinical grade PI3K and ER pathway inhibitors. Conclusions focused on the induction of apoptosis because the ability of PI3K inhibitors to induce cell death, rather than inhibit cell proliferation, is considered to be the best predictor of in vivo anti-tumor response [17]. The dual PI3K/mTOR inhibitor BGT226 generally produced the highest levels of apoptosis when combined with estrogen deprivation in sensitive cells, followed by the PI3K isoform selective inhibitor BKM120. In contrast, the level of apoptosis induced by the mTOR-selective inhibitor RAD001 in estrogen-deprived cells was modest by comparison, even in the most sensitive cells. Poor induction of apoptosis by RAD001 in estrogen-deprived ER-positive cells is consistent with the results of a randomized phase 2 trial (NCT00107016) that evaluated the efficacy of the aromatase inhibitor letrozole and RAD001 as neoadjuvant treatment for ER-positive breast cancer. Despite greater inhibition of tumor proliferation, the pathological complete response rate was not increased by RAD001 over that observed using letrozole alone - suggesting no clinically significant increase in cell death was achieved [23]. Our data suggest that if tolerable at active doses, direct inhibitors of PI3K might be more effective in this setting.

The sensitizing effect of PIK3CA mutation to the dual PI3K/mTOR inhibitor BEZ235 and to a selective Akt inhibitor in breast cancer cells has already been reported 
$[9,17]$. These studies included few PIK3CA wild-type ER-positive HER2-negative cells, however, and it was not clear how PIK3CA mutation impacts PI3K inhibitor sensitivity in the setting of estrogen deprivation. Our data support the conclusion that PIK3CA mutation confers sensitivity to PI3K pathway inhibitors in the setting of new agents in clinical development and that this differential effect is maintained under estrogen-deprived conditions. However, the impact of estradiol on PI3K pathway inhibitor activity in PIK3CA mutant cells was not uniform. Estradiol suppressed apoptosis induced by BGT226 in MCF7 and T47D cells but not in BT-483 cells. The identification of additional biomarkers will probably therefore be necessary to fully predict the efficacy of PI3K/endocrine combination therapy in PIK3CA mutant ER-positive tumors. Consistent with previous reports, the effect of PTEN mutation on the sensitivity of ER-positive cells to PI3K inhibitors also appears complex $[9,17]$. Whereas the PTEN-negative MDA-MB-415 and ZR75-1 lines were sensitive to both BGT226 and BKM120, the CAMA-1 line, which is PTEN mutant but does express low amounts of PTEN, was resistant to both inhibitors. The reasons for the inconsistent effects of PTEN deficiency on PI3K pathway inhibitor sensitivity in ER-positive cells will also require further study.

Estradiol is thought to prevent apoptosis through plasma-membrane-initiated or nongenomic signaling by the ER through activation of the PI3K and MAPK pathways $[24,25]$. Consistent with these reports, our results indicate that transduction of the estradiol survival signal increases PI3K inhibitor dose requirements in some ERpositive breast cancer cells (for example, MCF7 and T47D cells) but not others (BT-483, MDA-MB-415 and ZR75-1 cells). Interestingly, our results also show that the anti-apoptotic activity of estradiol is preserved in breast cancer cells that do not require estradiol for proliferation as a consequence of prolonged estrogen deprivation (Figure 6). The decoupling of the proliferative and anti-apoptotic effects of estrogen suggests that continuing estrogen deprivation in progressing patients and adding a PI3K inhibitor might be a strategy worth testing.

The optimal endocrine combination with PI3K inhibition in cells resistant to estrogen deprivation is a critical consideration since the overwhelming majority of patients with advanced breast cancer have already been treated with an aromatase inhibitor in the adjuvant setting. Treatment options include an anti-estrogen (such as the ER downregulator fulvestrant) [26] or therapy with low-dose estradiol [21]. We modeled these secondline approaches in contrasting LTED cell lines, one where ER expression was maintained and one where it was lost, in order to reflect the clinical observation that upon disease progression ER is downregulated in a proportion of cases $[27,28]$. Both LTED lines were found to be relatively resistant to PI3K inhibitors compared with the parental lines, consistent with reports that acquiring the ability to grow in the absence of estrogen is associated with increased PI3K and MAPK signaling [29]. The use of fulvestrant efficiently sensitized MCF7 LTED cells to both BKM120 and BGT226, however, consistent with a key role for ligand-independent ER activity in PI3K inhibitor resistance. The use of estradiol to revert the LTED phenotype, followed by re-institution of estrogen deprivation, is a viable alternative strategy; however, the restoration of sensitivity to PI3K inhibition with this approach appeared less profound than with fulvestrant treatment.

Taken together our data provide a rationale for combining estrogen deprivation with PI3K inhibitors for the treatment of PIK3CA mutant estrogen-dependent, ERpositive tumors and for the combination of fulvestrant with PI3K inhibitors in patients with ER-positive, aromatase-inhibitor-resistant disease. However, further studies will be necessary to effectively translate these preclinical data into the clinical setting. These studies could include additional preclinical modeling in PIK3CA wild-type estrogen-deprivation-resistant tumor lines to determine whether PIK3CA mutation is necessary in endocrine-resistant tumors to confer PI3K inhibitor sensitivity. In addition, incorporating biomarker (PIK3CA mutation, Ki67 tumor cell proliferation and cell death markers) analysis in early-phase PI3K inhibitor trials may aid in identifying patients most likely to benefit from these therapeutic agents.

To address the prevalence of the target population for a fulvestrant/PI3K inhibitor trial for second-line treatment of ER-positive PIK3CA mutant relapsed disease, we analyzed 51 advanced disease biopsies from both ERpositive and ER-negative cases for PIK3CA mutation and correlated findings with the clinical trajectory of the patients. While patients with ER-positive PIK3CA mutant tumors tended to relapse later than patients with ER-negative or ER-positive PIK3CA wild-type tumors, the PIK3CA mutation prevalence in ER-positive relapsed disease was high (approximately 50\%). These findings are consistent with those recently reported by Dupont Jensen and colleagues on an analysis of 104 paired primary and metastatic breast tumors [30]. In this study, PIK3CA mutation was detected in $53 \%$ of the metastatic tumors and $45 \%$ of the primary tumors, indicating an apparent net gain in PIK3CA mutation in metastatic disease that was thought to be due to heterogeneity in the primary tumor. The high prevalence of PIK3CA mutation in metastatic or recurrent breast cancer suggests that PI3K-pathway-targeted therapeutics will be clinically relevant in this setting. These data also indicate that analysis of the recurrent disease will be 
necessary for selection of patients based upon tumor PIK3CA mutation status.

\section{Conclusions}

Estrogen-dependent, ER-positive breast cancers with PIK3CA mutation and, possibly, PTEN loss will be most responsive to $\mathrm{PI} 3 \mathrm{~K}$ isoform inhibitors in combination with estrogen deprivation therapy. By increasing tumor cell death, these combinations may be sufficient to eradicate ER-positive cells - thereby preventing acquired endocrine resistance. When estrogen derivation resistance and relapse does occur in PIK3CA mutant ER-positive cells, fulvestrant combined with PI3K inhibition may be an effective salvage approach - and screening of relapse biopsies for PIK3CA mutation confirms that a population of patients who meet these criteria is easy to identify.

\begin{abstract}
Abbreviations
CSS: charcoal-stripped serum; ER: estrogen receptor; ERK: extracellular signalregulated kinase; FBS: fetal bovine serum; HER2: human epidermal growth factor receptor 2 ; $I_{50}$ : half maximal inhibitory concentration; $L C_{50}: 50 \%$ lethal concentration; LTED: long-term estrogen deprivation; LTED-R: estrogenretreated long-term estrogen-deprived; MAPK: mitogen-activated protein kinase; mTOR: mammalian target of rapamycin; p-Akt: phospho-Akt; p-ERK: phospho-ERK; PI3K: phosphatidylinositol-3-kinase; PI3KCA: phosphoinositide-3kinase, catalytic, a-polypeptide; p-S6: phospho-Ser235/236 S6; PTEN: phosphatase and tensin homolog; siRNA: small interfering RNA; STED: shortterm estrogen deprivation; TUNEL: Terminal deoxynucleotidyl transferasemediated nick-end labeling.
\end{abstract}

\section{Acknowledgements}

The present work was supported in part by awards from the NIH (R01 CA095614) and the Barnes-Jewish Hospital Research Foundation (to MJE) and the Siteman Cancer Center Breast Cancer Research Development Award (CXM). RJC was supported in part by an award from the Edward Mallinckrodt, Jr Foundation. CGS was supported in part by an ASCO Cancer Foundation Long-term International Fellowship award and the Division of Oncology, Washington University School of Medicine. The authors thank the Alvin J. Siteman Comprehensive Cancer Center at Washington University School of Medicine and Barnes-Jewish Hospital in St Louis, MO, for the use of the High Speed Cell Sorter Core. The Siteman Comprehensive Cancer Center is supported in part by NCl Cancer Center Support Grant \#P30 CA91842. The authors would like to thank Novartis for the provision of clinical-grade PI3K pathway inhibitors and for productive discussion with Dr Wolfgang Hackl. They would also like to thank Dr Jason Weber for critical review of the manuscript.

\begin{abstract}
Author details
'Department of Hematology-Oncology, School of Medicine, Pontificia Universidad Catolica de Chile, Lira 85, 4th floor, Santiago 8330023, Chile. ${ }^{2}$ Division of Oncology, Department of Medicine, Washington University in St Louis, 660 S Euclid Avenue, Campus Box 8069, St Louis, MO 63110, USA. ${ }^{3}$ Siteman Comprehensive Cancer Center, $660 \mathrm{~S}$ Euclid Avenue, Campus Box 8100, St Louis, MO 63110, USA. ${ }^{4}$ Division of Biostatistics, Department of Medicine, Washington University in St Louis, 660 S Euclid Avenue, Campus Box 8067, St Louis, MO 63110, USA.
\end{abstract}

\section{Authors' contributions}

CGS, CXM, RJC and MJE contributed to the experimental design. CGS, CXM, RJC, CP and LL were responsible for performing experiments and data analysis. TG coordinated sample collection of patients with recurrent and metastatic breast cancer. FG was responsible for statistical analysis of tumor samples from advanced breast cancer patients. CGS, CXM, RJC, and MJE contributed to manuscript preparation.

\section{Competing interests}

MJE has received honoraria and grants and has served as a consultant for AstraZeneca, Novartis and Pfizer. No pharmaceutical company funding was received for this project. The authors declare that they have no competing interests.

Received: 17 November 2010 Revised: 24 January 2011

Accepted: 1 March 2011 Published: 1 March 2011

\section{References}

1. Early Breast Cancer Trialists' Collaborative Group: Effects of chemotherapy and hormonal therapy for early breast cancer on recurrence and 15-year survival: an overview of the randomised trials. Lancet 2005, 365:1687-1717.

2. Dowsett M, Smith IE, Ebbs SR, Dixon JM, Skene A, Griffith C, Boeddinghaus I, Salter J, Detre S, Hills M, Ashley S, Francis S, Walsh G, $A^{\prime}$ Hern R: Proliferation and apoptosis as markers of benefit in neoadjuvant endocrine therapy of breast cancer. Clin Cancer Res 2006, 12:1024s-1030s.

3. Goss PE, Ingle JN, Martino S, Robert NJ, Muss HB, Piccart MJ, Castiglione M, Tu D, Shepherd LE, Pritchard KI, Livingston RB, Davidson NE, Norton L, Perez EA, Abrams JS, Therasse P, Palmer MJ, Pater JL: A randomized trial of letrozole in postmenopausal women after five years of tamoxifen therapy for early-stage breast cancer. N Engl J Med 2003, 349:1793-1802.

4. Liu P, Cheng H, Roberts TM, Zhao JJ: Targeting the phosphoinositide 3kinase pathway in cancer. Nat Rev Drug Discov 2009, 8:627-644.

5. Crowder RJ, Phommaly C, Tao Y, Hoog J, Luo J, Perou CM, Parker JS, Miller MA, Huntsman DG, Lin L, Snider J, Davies SR, Olson JA Jr, Watson MA, Saporita A, Weber JD, Ellis MJ: PIK3CA and PIK3CB inhibition produce synthetic lethality when combined with estrogen deprivation in estrogen receptor-positive breast cancer. Cancer Res 2009, 69:3955-3962.

6. Maruyama N, Miyoshi Y, Taguchi T, Tamaki Y, Monden M, Noguchi S: Clinicopathologic analysis of breast cancers with PIK3CA mutations in Japanese women. Clin Cancer Res 2007, 13:408-414.

7. Kalinsky K, Jacks LM, Heguy A, Patil S, Drobnjak M, Bhanot UK, Hedvat CV, Traina TA, Solit D, Gerald W, Moynahan ME: PIK3CA mutation associates with improved outcome in breast cancer. Clin Cancer Res 2009, 15:5049-5059.

8. Gazdar AF, Kurvari V, Virmani A, Gollahon L, Sakaguchi M, Westerfield M, Kodagoda D, Stasny V, Cunningham HT, Wistuba II, Tomlinson G, Tonk V, Ashfaq R, Leitch AM, Minna JD, Shay JW: Characterization of paired tumor and non-tumor cell lines established from patients with breast cancer. Int J Cancer 1998, 78:766-774.

9. She QB, Chandarlapaty S, Ye Q, Lobo J, Haskell KM, Leander KR, DeFeoJones D, Huber HE, Rosen N: Breast tumor cells with PI3K mutation or HER2 amplification are selectively addicted to Akt signaling. PLOS ONE 2008, 3:e3065.

10. Vasudevan KM, Barbie DA, Davies MA, Rabinovsky R, McNear CJ, Kim JJ, Hennessy BT, Tseng H, Pochanard P, Kim SY, Dunn IF, Schinzel AC, Sandy P, Hoersch S, Sheng Q, Gupta PB, Boehm JS, Reiling JH, Silver S, Lu Y, StemkeHale K, Dutta B, Joy C, Sahin AA, Gonzalez-Angulo AM, Lluch A, Rameh LE, Jacks $T$, Root DE, Lander $E S$, et al: AKT-independent signaling downstream of oncogenic PIK3CA mutations in human cancer. Cancer Cell 2009, 16:21-32.

11. Lee-Hoeflich ST, Crocker L, Yao E, Pham T, Munroe X, Hoeflich KP, Sliwkowski MX, Stern HM: A central role for HER3 in HER2-amplified breast cancer: implications for targeted therapy. Cancer Res 2008, 68:5878-5887.

12. Engelman JA: Targeting PI3K signalling in cancer: opportunities, challenges and limitations. Nat Rev Cancer 2009, 9:550-562.

13. Maira SM, Stauffer F, Brueggen J, Furet P, Schnell C, Fritsch C, Brachmann S, Chene P, De Pover A, Schoemaker K, Fabbro D, Gabriel D, Simonen M, Murphy L, Finan P, Sellers W, Garcia-Echeverria C: Identification and characterization of NVP-BEZ235, a new orally available dual phosphatidylinositol 3-kinase/mammalian target of rapamycin inhibitor with potent in vivo antitumor activity. Mol Cancer Ther 2008, 7:1851-1863.

14. Serra V, Markman B, Scaltriti M, Eichhorn PJ, Valero V, Guzman M, Botero ML, Llonch E, Atzori F, Di Cosimo S, Maira M, Garcia-Echeverria C, Parra JL, Arribas J, Baselga J: NVP-BEZ235, a dual PI3K/mTOR inhibitor, prevents PI3K signaling and inhibits the growth of cancer cells with activating PI3K mutations. Cancer Res 2008, 68:8022-8030. 
15. O'Reilly KE, Rojo F, She QB, Solit D, Mills GB, Smith D, Lane H, Hofmann F, Hicklin DJ, Ludwig DL, Baselga J, Rosen N: mTOR inhibition induces upstream receptor tyrosine kinase signaling and activates Akt. Cancer Res 2006, 66:1500-1508.

16. Breuleux M, Klopfenstein M, Stephan C, Doughty CA, Barys L, Maira SM, Kwiatkowski D, Lane HA: Increased AKT S473 phosphorylation after mTORC1 inhibition is rictor dependent and does not predict tumor cell response to PI3K/mTOR inhibition. Mol Cancer Ther 2009, 8:742-753.

17. Brachmann SM, Hofmann I, Schnell C, Fritsch C, Wee S, Lane H, Wang S, Garcia-Echeverria C, Maira SM: Specific apoptosis induction by the dual PI3K/mTor inhibitor NVP-BEZ235 in HER2 amplified and PIK3CA mutant breast cancer cells. Proc Natl Acad Sci USA 2009, 106:22299-22304.

18. Song RX, Mor G, Naftolin F, McPherson RA, Song J, Zhang Z, Yue W, Wang J, Santen RJ: Effect of long-term estrogen deprivation on apoptotic responses of breast cancer cells to 17ß-estradiol. J Natl Cancer Inst 2001, 93:1714-1723.

19. Lewis JS, Meeke K, Osipo C, Ross EA, Kidawi N, Li T, Bell E, Chandel NS, Jordan VC: Intrinsic mechanism of estradiol-induced apoptosis in breast cancer cells resistant to estrogen deprivation. J Natl Cancer Inst 2005, 97:1746-1759.

20. Wakeling $A E$, Dukes $M$, Bowler J: A potent specific pure antiestrogen with clinical potential. Cancer Res 1991, 51:3867-3873.

21. Ellis MJ, Gao F, Dehdashti F, Jeffe DB, Marcom PK, Carey LA, Dickler MN, Silverman P, Fleming GF, Kommareddy A, Jamalabadi-Majidi S, Crowder R, Siegel BA: Lower-dose vs high-dose oral estradiol therapy of hormone receptor-positive, aromatase inhibitor-resistant advanced breast cancer: a phase 2 randomized study. JAMA 2009, 302:774-780.

22. Saal LH, Holm K, Maurer M, Memeo L, Su T, Wang X, Yu JS, Malmstrom PO, Mansukhani M, Enoksson J, Hibshoosh H, Borg A, Parsons R: PIK3CA mutations correlate with hormone receptors, node metastasis, and ERBB2, and are mutually exclusive with PTEN loss in human breast carcinoma. Cancer Res 2005, 65:2554-2559.

23. Baselga J, Semiglazov V, van Dam P, Manikhas A, Bellet M, Mayordomo J, Campone M, Kubista E, Greil R, Bianchi G, Steinseifer J, Molloy B, Tokaji E, Gardner H, Phillips P, Stumm M, Lane HA, Dixon JM, Jonat W, Rugo HS: Phase II randomized study of neoadjuvant everolimus plus letrozole compared with placebo plus letrozole in patients with estrogen receptor-positive breast cancer. J Clin Oncol 2009, 27:2630-2637.

24. Kousteni S, Bellido T, Plotkin LI, O'Brien CA, Bodenner DL, Han L, Han K, DiGregorio GB, Katzenellenbogen JA, Katzenellenbogen BS, Roberson PK, Weinstein RS, Jilka RL, Manolagas SC: Nongenotropic, sex-nonspecific signaling through the estrogen or androgen receptors: dissociation from transcriptional activity. Cell 2001, 104:719-730.

25. Fernando Rl, Wimalasena J: Estradiol abrogates apoptosis in breast cancer cells through inactivation of BAD: Ras-dependent nongenomic pathways requiring signaling through ERK and Akt. Mol Biol Cell 2004, 15:3266-3284.

26. Chia S, Gradishar W, Mauriac L, Bines J, Amant F, Federico M, Fein L, Romieu G, Buzdar A, Robertson JF, Brufsky A, Possinger K, Rennie P, Sapunar F, Lowe E, Piccart M: Double-blind, randomized placebo controlled trial of fulvestrant compared with exemestane after prior nonsteroidal aromatase inhibitor therapy in postmenopausal women with hormone receptor-positive, advanced breast cancer: results from EFECT. J Clin Oncol 2008, 26:1664-1670.

27. Johnston SR, Saccani-Jotti G, Smith IE, Salter J, Newby J, Coppen M, Ebbs SR, Dowsett M: Changes in estrogen receptor, progesterone receptor, and $\mathrm{pS} 2$ expression in tamoxifen-resistant human breast cancer. Cancer Res 1995, 55:3331-3338.

28. Thompson A, Jordan L, Quinlan P, Anderson E, Skene A, Dewar J, Purdie C, Breast Recurrence in Tissues Study Group T: Prospective comparison of switches in biomarker status between primary and recurrent breast cancer: the Breast Recurrence In Tissues Study (BRITS). Breast Cancer Res 2010, 12:R92.

29. Yue W, Fan P, Wang J, Li Y, Santen RJ: Mechanisms of acquired resistance to endocrine therapy in hormone-dependent breast cancer cells. J Steroid Biochem Mol Biol 2007, 106:102-110.

30. Dupont Jensen J, Laenkholm AV, Knoop A, Ewertz M, Bandaru R, Weihua L, Hackl W, Barrett JC, Gardner H: PIK3CA mutations may be discordant between primary and corresponding metastatic disease in Breast Cancer. Clin Cancer Res 2010, 17:667-67731 [http://www.sanger.ac.uk], Wellcome Trust Sanger Institute.

\section{doi:10.1186/bcr2833}

Cite this article as: Sanchez et al: Preclinical modeling of combined phosphatidylinositol-3-kinase inhibition with endocrine therapy for estrogen receptor-positive breast cancer. Breast Cancer Research 2011 13: R21.

\section{Submit your next manuscript to BioMed Central and take full advantage of:}

- Convenient online submission

- Thorough peer review

- No space constraints or color figure charges

- Immediate publication on acceptance

- Inclusion in PubMed, CAS, Scopus and Google Scholar

- Research which is freely available for redistribution

Submit your manuscript at www.biomedcentral.com/submit
Biomed Central 